\title{
Eco-trends in the decoration of facades of houses of modern industrial series
}

\author{
Ekaterina Dorozhkina ${ }^{1, *}$, Alexander Pastukhov ${ }^{1}$, Anastasia Averyanova ${ }^{1}$, and Kirill \\ Stepanov $^{1}$ \\ ${ }^{1}$ University of Civil Engineering, 26, Yaroslavskoe highway, Moscow 129337, Russia
}

\begin{abstract}
The purpose of the research is to study and systematize the solutions of facade structures for prefabricated and precast-monolithic construction. The article considers single-layer, two-layer and three-layer external wall panels. An analysis of design solutions was carried out in terms of ensuring energy efficiency requirements. Possible options for finishing buildings with external walls made of large-sized elements were analyzed, taking into account their design solutions. The scientific novelty of the article lies in considering the issue of facade decoration both from the point of view of architectural expressiveness and energy efficiency. It also compares the most common types of external wall panels based on the thermal characteristics and geometric dimensions of the materials used and, as a result, their economic feasibility. As a result of the analysis, it can be concluded that modern solutions for prefabricated external walls have great importance for the implementation of design solutions and finishing the facade of buildings from large-size prefabricated elements. The best indicators of all the options considered are the two-layer hinged and threelayer external wall panels.
\end{abstract}

\section{Introduction}

The formation of the residential real estate fund is one of the priority directions of the state policy in Russian Federation. The Decree of the Government of the Russian Federation evidenced of that at December 17, 2010 N1050 "On the federal target program" Housing "for 2015-2020" and the Government Decree No. 497-PP of 01.08.2017 The program for renovating the housing stock in Moscow" particular.

The implementation of these programs should be largely ensured by the optimization of technological processes. Expensive and time-consuming are reduced both for the construction of buildings and for engineering works [1]. It can be achieved by a high degree of industrialization of the construction industry [2]. The reduction in the share of construction and installation work is ensured by the use of prefabricated facilities. Optimization of design work is often determined by digitalization [3].

The projects of mass series and repeated using have the greatest economic attractiveness for civil and, in particular, housing construction. Most of constructions were built using the precast reinforced concrete technology [4], less frequently the precast-monolithic building

* Corresponding author: $\underline{\text { dor-ea } @ \text { yandex.ru }}$ 
system is used [5]. Moreover, such tendencies characterize not only apartment buildings, but buildings intended for temporary stay - hotels, hostels and others [6].

Industrial construction is usually called mass or typical [7]. This characteristic is associated with solutions of the same type [8]. In this case, both space-planning solutions and the architectural expressiveness of the facades. An example of multi-storey residential buildings of one of the most common in Moscow and a number of other cities is P-44T, P$55 \mathrm{~T}$ is shown in Figure 1.

Despite the attractiveness of prefabricated construction, standardized facades of residential buildings are losing their relevance today. This has been repeatedly noted both in popular science articles $[9,10]$ and during discussion at conferences at various levels [11]. This undoubtedly indicates the importance of the problem posed for modern mass architecture. In view of this, the professional community is faced with the task of forming individual solutions for buildings of mass series without losing other characteristics.

\section{Subject, tasks and research methods}

The purpose of this work is to study and systematize solutions for facade structures of precast reinforced concrete and precast-monolithic construction.

The subject of the research is the structural solutions facades of prefabricated and precast-monolithic construction.

Research objectives:

- identify groups of criteria for assessing facade structures;

- consider possible design solutions for external wall panels, implemented in modern construction practice, taking into account the selected groups of criteria;

- consider the possibility of implementing design solutions in the decoration of facades and the design features.

As the main research method was used a systematic analysis of the regulatory framework for the design and project documentation of modern industrial house series.

\section{Results and discussion}

A set of requirements is imposed to the structures of external walls. It is also important to consider economic, aesthetic and operational requirements [12,13]. Additionally, aspects of environmental friendliness of both production and future buildings in general can be considered $[14,15]$. The system of criteria for evaluating the design solutions of facades is shown in figure 1.

A two-layer panel is a multilayer structure consisting of a load-bearing layer of light or heavy concrete of class B10-B15 with a density of at least $1000 \mathrm{~kg} / \mathrm{m} 3$ and an insulating layer of lightweight concrete or rigid heat-insulating plates. This constructive solution requires additional finishing, made in the form of hinged structures.

The shell is another type of the facade design. It is a two-layer curtain wall panel. An insulating layer in the form of stone wool or expanded polystyrene is located between the concrete dowels. The insulating layer act as stiffeners. Reinforcement of the product is carried out with reinforcing meshes, as well as frames located in horizontal and vertical ribs. The constructive solution is shown in the figure 2 .

Technologically, the implementation of the external structure is carried out in the following sequence: an external wall panel-shell is installed and fastened to the supporting base of the building using embedded parts located at the ends of the product; from inside the room, a partition is erected from piece small-sized elements. This design option is most 
applicable for prefabricated monolithic buildings. This technological solution leads to a significant reduction in construction time.

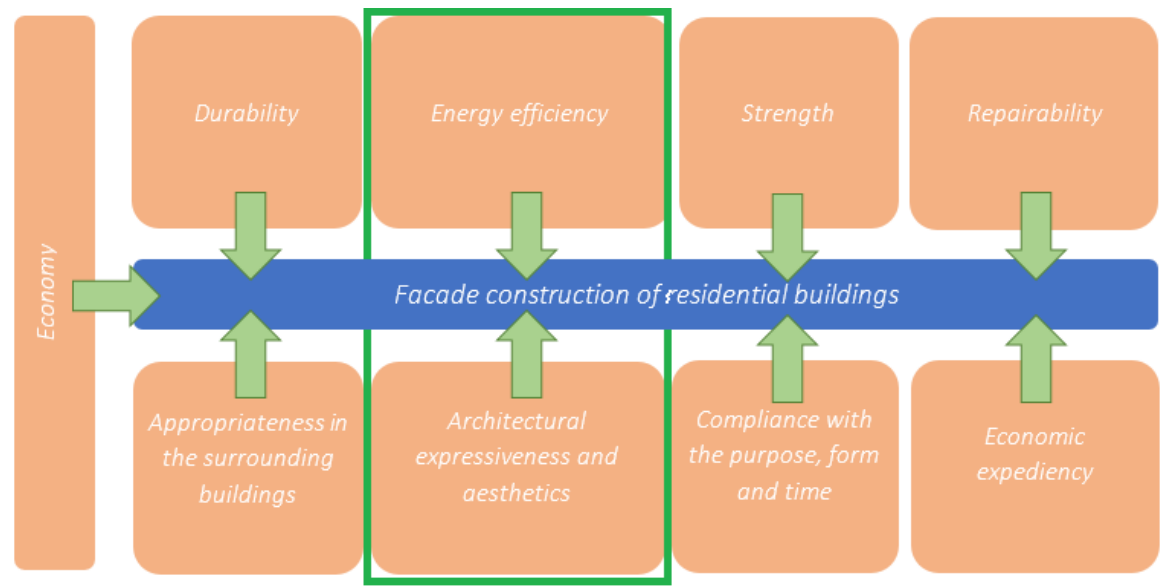

Fig. 1. The system of criteria for evaluating the design solutions of facades.

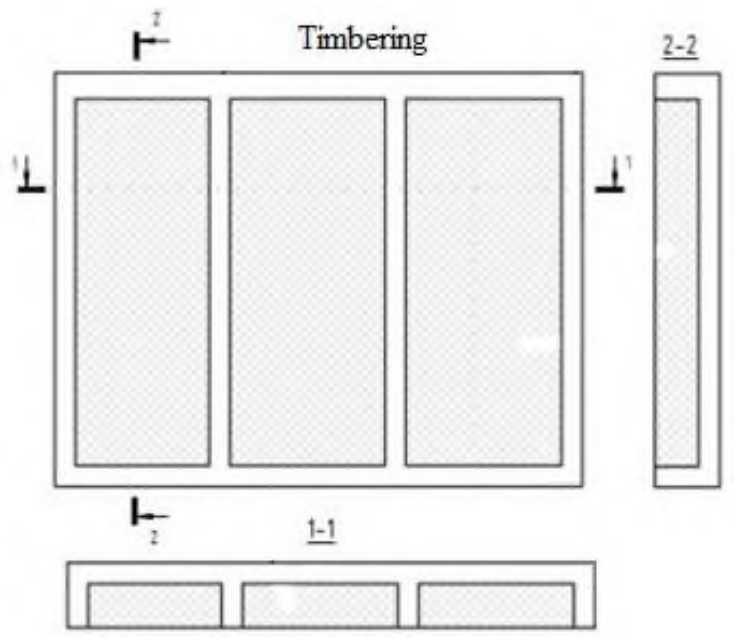

Fig. 2. An example of a constructive solution for two-layer curtain wall panel.

Three-layer panels are the most common solution for prefabricated construction. It consists of two thin reinforced concrete slabs and an effective thermal insulation layer between them. The most technologically advanced insulation material is rigid expanded polystyrene plates. The connection of reinforced concrete layers can be performed with reinforced concrete dowels or flexible stainless steel ties. Normally, the thickness of the layers is taken at least $80 \mathrm{~mm}$ for the inner layer of concrete and at least $50 \mathrm{~mm}$ for the outer layer. The thickness of the insulation layer is determined by a heat engineering calculation, taking into account the climatic characteristics of the construction region.

The design of external wall panels is not uniform in terms of energy efficiency. The value of the resistance to heat transfer of the building envelope is a quantitative assessment of the thermal performance of the building envelope. It allows to establish the compliance of the design with regulatory requirements, to establish real heat losses, to check design and 
design solutions. In addition to the constructive solution of wall panels, the overall dimensions and filling of window and door openings are of no small importance.

Heat conductive inclusions are an integral cause of thermal heterogeneity. When testing and inspecting structures, temperature differences are observed on the surface. Lower temperature spots are on the warm surface of the panel and higher temperature spots are on the cold side of the panel in standard tests.

Considering the aesthetic side of the issue, the decorative finish of the facade is of great importance $[16,17]$. It should be noted that the adopted facade decoration can significantly change the thermal properties of the structure. The decision made must be confirmed by appropriate calculations to assess the thermal and moisture state.

Usually, plastering of the concrete surface of the outer layer was used, followed by painting according to the color passport. This was typical of mass production buildings and pre-fabricated large-scale reusable projects developed in the USSR and the post-Soviet period. Undoubtedly, this solution was distinguished by its simplicity of execution. However, its main disadvantage has been repeatedly noted its susceptibility to adverse environmental influences. The painted facade required regular renovation, and the structural solutions of the outer walls often do not meet modern energy efficiency requirements.

Decorative plaster is often used for modern projects. It is shown in figure 3 . This makes it possible to form a relief finish of large-panel external walls of residential buildings of mass series. In this case, a textured surface is formed, it becomes possible to apply decorative patterns. This option is more advantageous than the traditional solution.
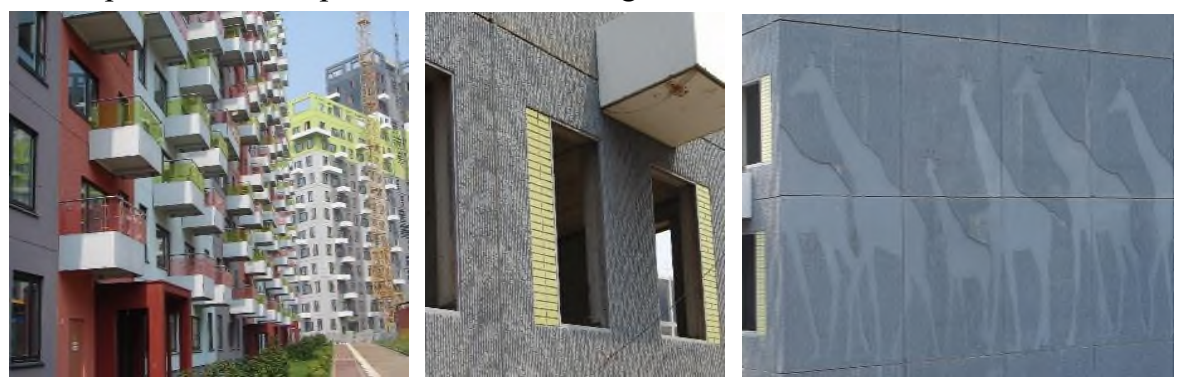

Fig. 3. Application of decorative plaster finishing (for example, Apartment Complex Edalgo, Moscow).

The decoration of the external wall panels with glazed tiles was more technological solution. The facades of many series are made according to this principle. Tiled facades have different graphic solutions in a modern interpretation. Examples of them are shown in the figure 4.
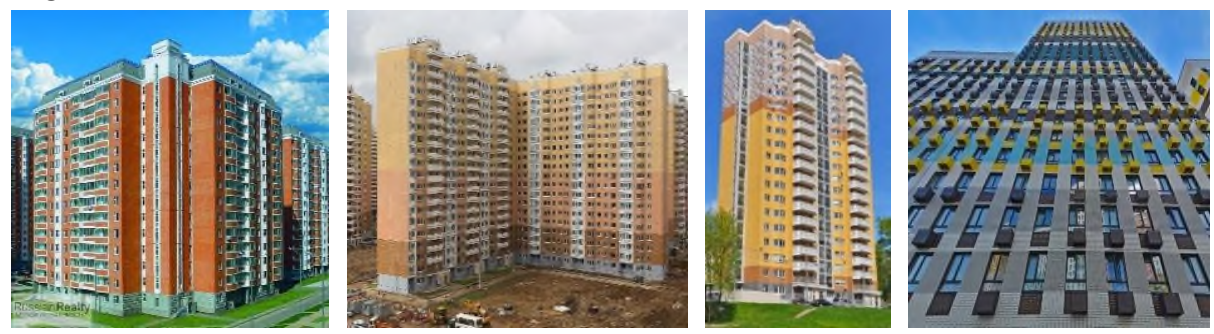

Fig. 4. Examples of tiled facades made of large elements.

Brick can be considered as an unconventional material for finishing facades made of large-sized elements [18]. With such solution, the brick is monolithic in uncured concrete, while forming one or another pattern or the required volumetric elements of the facade. 
Traditionally, a horizontal layout is used for load-bearing elements. When using bricks as a finishing material, the layout options can be different, like horizontal, vertical, with or without binding, as well as the type of brick itself. Glazed bricks can also be used for the decorative layer. Modern technologies make it possible to produce bricks of various shades, which is very important in the implementation of the architectural concept. Examples of solutions for the facades of large-panel buildings using brickwork are shown in the figure 5 .
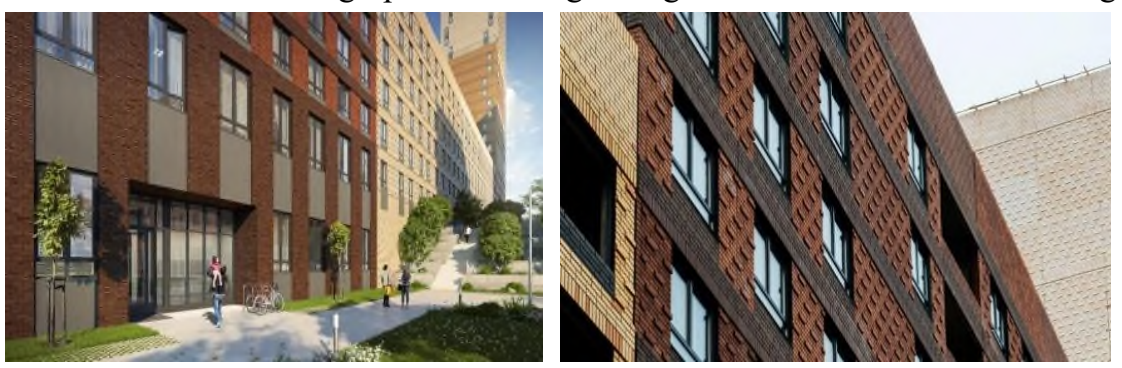

Fig. 5. Examples of facades made of large-sized elements, finished with bricks (Apartment Complex Akademika Pavlova, Moscow).

In order to individualize the appearance of buildings, various options for light overhead elements like framing entrances and windows, cornices, pilasters, and others can also be applied. Some modern production facilities allow the production of wall panels with the provided volumetric elements.

Table 1. Classification of technical solutions and options facades of large-sized elements.

\begin{tabular}{|c|c|c|c|c|}
\hline & $\begin{array}{c}\text { A single- } \\
\text { layer } \\
\text { external wall } \\
\text { panel }\end{array}$ & $\begin{array}{l}\text { A two-layer } \\
\text { panel }\end{array}$ & $\begin{array}{l}\text { A two-layer } \\
\text { curtain wall } \\
\text { panel }\end{array}$ & $\begin{array}{c}\text { A three-layer } \\
\text { panel }\end{array}$ \\
\hline Carrier material & $\begin{array}{c}\text { cellular } \\
\text { concrete } \\
\rho=600-700 \\
\mathrm{~kg} / \mathrm{m} 3\end{array}$ & $\begin{array}{c}\text { cellular or } \\
\text { dense concrete } \\
\rho=1000-2500 \\
\mathrm{~kg} / \mathrm{m} 3\end{array}$ & absent & $\begin{array}{c}\text { cellular or } \\
\text { dense concrete } \\
\rho=1000-2500 \\
\mathrm{~kg} / \mathrm{m} 3\end{array}$ \\
\hline $\begin{array}{c}\text { Insulation layer } \\
\text { material }\end{array}$ & absent & $\begin{array}{c}\text { styrofoam } \\
\rho=100-150 \\
\mathrm{~kg} / \mathrm{m} 3\end{array}$ & $\begin{array}{c}\text { styrofoam } \\
\rho=45-100 \\
\mathrm{~kg} / \mathrm{m} 3\end{array}$ & $\begin{array}{c}\text { styrofoam } \\
\rho=45-100 \\
\mathrm{~kg} / \mathrm{m} 3\end{array}$ \\
\hline $\begin{array}{l}\text { Outer layer } \\
\text { material }\end{array}$ & absent & absent & $\begin{array}{c}\text { cellular or } \\
\text { dense concrete } \\
\rho=1000-2500 \\
\mathrm{~kg} / \mathrm{m} 3\end{array}$ & $\begin{array}{c}\text { cellular or } \\
\text { dense concrete } \\
\rho=1000-2500 \\
\mathrm{~kg} / \mathrm{m} 3\end{array}$ \\
\hline $\begin{array}{l}\text { Recommended } \\
\text { structure } \\
\text { thickness, mm } \\
\text { (Moscow) }\end{array}$ & 740 & 130 & 135 & 110 \\
\hline \multicolumn{5}{|c|}{ Facade finishing options } \\
\hline $\begin{array}{c}\text { Ventilated } \\
\text { facade }\end{array}$ & yes & * & $*$ & * \\
\hline $\begin{array}{l}\text { Decorative } \\
\text { plaster }\end{array}$ & yes & yes & yes & yes \\
\hline Tile & not & not & yes & yes \\
\hline Brick & $* *$ & not & yes & yes \\
\hline
\end{tabular}

* It is possible to use a ventilated facade during reconstruction.

** It is possible to use a three-layer outer wall as a constructive outer layer with a thickness of $120 \mathrm{~mm}$. 
Thus, facade decoration with modern construction practice can be represented by the following options:

- the use of facade solutions that are not typical for prefabricated structures;

- the use of decorative plaster;

- the use of non-traditional materials for panel construction;

- combinations of solutions.

Table 1 provides a classification of technical solutions and options for finishing facades made of large-sized elements.

\section{Conclusions}

As a result of the work on the article, modern facade solutions for prefabricated or prefabricated monolithic buildings were analyzed. The variant of external walls made of large-sized elements was identified as one of the most promising for modern industrial construction.

The analysis of design solutions of external wall panels from the standpoint of ensuring energy efficiency requirements is carried out. Possible options for finishing buildings with external walls made of large-sized elements were analyzed, taking into account their design solutions.

Modern solutions for prefabricated exterior walls are of great importance for the implementation of design solutions when finishing the facade of buildings from large-size prefabricated elements.

\section{References}

1. S.V. Nikolaev, A.K. Schreiber, J.G. Khayutin, Housing 5, 3-8 (2014)

2. A.V. Pastukhov, E.A. Dorozhkina, I.P. Leskovskii, IOP Conference Series: Materials Science and Engineering 537, 042075 (2019)

3. E. Dorozhkina, A. Pastukhov, IOP Conference Series: Earth and Environmental Science 272, 032235 (2019)

4. S.V. Nikolaev, Housing 3, 3-7 (2018)

5. S.V. Nikolaev, Content: Function, design, environment in the architecture of buildings Collection of abstracts of the All-Russian scientific-practical conference, 15-16 (2019)

6. A.V. Popov, International Journal of Civil Engineering and Technology 9 (11), 25262536 (2018)

7. A.V. Popov Amazonia Investiga 8 (19), 179-190 (2019)

8. A.I. Finogenov, A.V. Popov, International Journal of Engineering and Advanced Technology 8 (6), 975-979 (2019)

9. V.A.K. Alavsi, V.M. Molchanov, Bulletin of the Tomsk State University of Architecture and Civil Engineering 22 (2), 55-71 (2020)

10. https://varlamov.ru/3495721.html

11. https://www.archplatforma.ru/?act=1\&catg=19\&nwid=2700

12. E Dorozhkina, IOP Conference Series: Materials Science and Engineering, 262, 012059 (2017)

13. I.S. Rodionovskaja, E.A. Dorozhkina, IOP Conference Series: Materials Science and Engineering, 463, 042006 (2018) 
14. E.A. Dorozhkina, IOP Conference Series: Materials Science and Engineering 055070 (2019)

15. E. Dorozhkina, IOP Conference Series: Materials Science and Engineering 962, 042005 (2020)

16. A.N. Larionov, S.D.R. Al-Rubaye, Journal of Management Studies 6 (3), 44-54 (2020)

17. D.O. Babkina, R.Yu. Yanova, A.V. Popov, T.V. Sorokoumova, Ecology of urbanized territories 1, 70-74 (2019)

18. A.O. Aleks, International Journal of Design and Nature and Ecodynamics 15 (2), 205210 (2020) 